Bewegte Antike 


\title{
DRAMA
}

Beiträge zum antiken Drama und seiner Rezeption

Herausgegeben von

F. De Martino - J. A. López Férez G. Mastromarco - B. Seidensticker N. W. Slater - A. H. Sommerstein R. Stillers - P. Thiercy -

\author{
B. Zimmermann
}




\title{
Beiheft 17
}

\author{
Ulrich Eigler (Hrsg.)
}

\section{Bewegte Antike}

Antike Themen im modernen Film

\author{
Verlag J. B. Metzler \\ Stuttgart · Weimar
}


Die Deutsche Bibliothek - CIP-Einheitsaufnahme

\section{Eigler, Ulrich:}

Bewegte Antike: Antike Themen im modernen Film / Ulrich Eigler (Hrsg.)

- Stuttgart ; Weimar : Metzler, 2002

(Drama : Beiheft ; 17)

(M-\&-P-Schriftenreihe für Wissenschaft und Forschung)

ISBN 978-3-476-45287-0

ISBN 978-3-476-02842-6 (eBook)

DOI 10.1007/978-3-476-02842-6

Dieses Werk einschließlich aller seiner Teile ist urheberrechtlich geschützt. Jede Verwertung außerhalb der engen Grenzen des Urheberrechtsgesetzes ist ohne Zustimmung des Verlages unzulässig und strafbar. Das gilt insbesondere für Vervielfältigungen, Übersetzungen, Mikroverfilmungen und die Einspeicherung und Verarbeitung in elektronischen Systemen.

M \& P Schriftenreihe für Wissenschaft und Forschung

(C) 2002 Springer-Verlag GmbH Deutschland

Ursprünglich erschienen bei J.B.Metzlersche Verlagsbuchhandlung und Carl Ernst Poeschel Verlag GmbH in Stuttgart 2002

www.metzlerverlag.de

Info@metzlerverlag.de 


\section{Inhaltsverzeichnis}

\section{U. Eigler \\ Einführung}

\section{A. Wieber}

Auf Sandalen durch die Jahrtausende - eine Einführung in den Themenkreis „Antike und Film“

\section{Brütsch - T. Fuhrer}

Annäherung an eine fremde Welt: Fellini-Satyricon im

Spannungsfeld von klassischem Antikenfilm und literarischer Vorlage

\section{B. Zimmermann}

Fremde Antike? - P.P. Pasolinis Medea

\section{A. Forst}

Leidende Rächerin: Lars von Triers Medea

\section{P. Riemer}

Der sophokleische Ödipus im Spiegel von Pasolinis Edipo re

\section{H. Flashar}

Ausblick 